\title{
"Innovating the competitive edge: from research to impact in the forest value chain": half-century of FORMEC
}

\author{
S.A. Borz, M. Acuna, H.R. Heinimann, T. Palander, R. Spinelli
}

Borz S.A., Acuna M., Heinimann H.R., Palander T., Spinelli R., 2017. "Innovating the competitive edge: from research to impact in the forest value chain": half-century of FORMEC. Ann. For. Res. 60(2): 199-201.

Authors. Stelian Alexandru Borz (stelian.borz@unitbv.ro) - Faculty of Silviculture and Forest Engineering, 1 Şirul Beethoven, Braşov, România; Mauricio Acuna - Faculty of Arts, Business and Law, University of the Sunshine Coast, Sunshine Coast, Queensland, Australia; Hans Rudolf Heinimann - Department of Environmental Systems Science, ETH Zürich, Zürich, Switzerland; Teijo Palander - Faculty of Science and Forestry, Department of Forestry University of Eastern Finland, Joensuu, Finland; Raffaele Spinelli - CNR IVALSA, Consiglio Nazionale Delle Ricerche, Istituto per La Valorizzazione Del Legno e Delle Specie Arboree, Via Madonna Del Piano 10, I-50019, Sesto Fiorentino, Firenze, Italy.

Manuscript received November 28, 2017; revised November 29, 2017; accepted November 29, 2017; online first November 30, 2017.

Part of this issue of Annals of Forest Research tries to reflect a special, important event: the $50^{\text {th }}$ Anniversary of FORMEC - The International Symposium on Forestry Mechanization. Originating in former Czechoslovakia, FORMEC conferences represent the largest annually events in forest engineering, bringing together academia, scientists, practitioners and policy makers, who share experience and practices of the forest engineering domain. Year by year, FORMEC was held in different countries; this year it was organized for the first time in Romania - in Braşov, celebrating a very special occasion: half of century of FORMEC. Following the $48^{\text {th }}$ and $49^{\text {th }}$ FORMEC editions held in Austria and Poland, the motto of Brașov conference was: "Innovating the competitive edge: from research to impact in the forest value chain". Its aim was to present the state-of-the-art in knowledge and to promote discussions on how innovation could enhance sustainable wood mobilization and forest value chain competitiveness, emphasising key topics, such as the timber logging and transport, forest road engineering, use of biomass for bioenergy, ergonomics and work safety of forest operations and other wood supply chain challenges, as well as innovative forest equipment and emerging forest technology. Scientists, practitioners and policy makers from all over the world attended the jubilee edition, with more than 150 contributions, as 
oral presentations and posters. Thirty countries were represented, bringing together the international high-lead experience and know-how. Keynote speakers presented new issues and perspectives in forestry and forest engineering, and related fields - technology, financing, or forestry political agendas.

Energy production from biomass represents one of the most important future challenges for human society: the decreasing availability of traditional energy resources and the growing awareness of ecological responsibilities are pushing the development of renewable energy systems. Biomass is the single most important renewable energy source for Europe, both in terms of actual energy production and of technical and economical potential; outside Europe, bio-energy can contribute to ecosystem restoration and poverty alleviation. This could be a momentous opportunity for forestry, to become one of the main suppliers of high-quality energy biomass; its production may support productive silviculture, increase the financial sustainability of those forest systems currently neglected due a limited profitability, despite an obvious practical value. More specifically, the demand for energy biomass may revive the early thinning operations and the coppice management, subject of a serious concern of forest managers over recent decades. Of course, harvesting of forest biomass shall be conducted within the limits depicted in sustainable forestry, which reinforces the crucial role of forest engineering as a main source of cost-effective environmentally-sound solutions.

For instance, in Australia, in the last years, forest operations research has focused on investigating the impact of moisture content on biomass and log supply chain costs. Consequently, drying trials have been established, and predictive drying models have been developed for Eucalyptus species and radiata pine. Several tools such as MCPLAN and FastTRUCK have been developed to analyse the impacts of drying biomass and roundwood in the forest. Also, MCPLAN has been used to investigate alternative biomass supply chains 200 in Europe and Australia; it provides spatial and temporal solutions, which include volumes to be harvested per period and supply point, drying times for roundwood and biomass, and flows from supply to demand points. Preliminary results show that optimising supply chains with MCPLAN can result in $20 \%$ savings in fleet size, $18 \%$ savings in $\mathrm{CO}_{2}$ emissions, and reduction in supply chains costs of up to $2.5 \$ / \mathrm{m}^{3}$. FastTRUCK is a software tool developed to assist transport and forest managers in solving the daily truck scheduling problem. FastTRUCK uses a standard Simulated Annealing (SA) procedure, which is encoded in the $\mathrm{C}++$ programming language, using an object-oriented design. By implementing FastTRUCK savings of up to $15 \%$ in transport costs can be achieved. In addition to supply chain optimisation tools, new technologies such as multi-view photogrammetry and 3D image processing software have been investigated and successfully tested for the automated volumetric measurement of truckloads. Preliminary results indicate that multi-view photogrammetry could be implemented operationally as a more affordable alternative than laser scanning systems. Future research will compare photogrammetry, stereoscopy and laser scanning systems for volumetric measurements of logs and biomass, regarding their accuracy, costs and operational implementation. Another example comes from the Nordic timber trade market, which is subject to agreements regarding stem bucking regulations. These agreements should be made on the basis of techno-economic analysis, accounting for the effects of local forest operations on the multiple-objective decision environment, which includes e.g. the timber purchase from forest owners and lumber sales from a sawmill to abroad. The decision environment is further complicated by the allocation of a number of $\log$ chains to a forest industry during different periods. In practice, this problem has been solved by applying different stem bucking instructions in harvesters. Due to the complex nature of the timber trade, single-objective so- 
lutions cannot be directly used to solve the problem in a manner that is techno-economically relevant to the forest owners and industries. Therefore, the most efficient stem bucking outcome is achieved by the multi-objective methods, when the bucking instructions of stands are subjected to the automatic classifications of local forest operations. Using these measurements the simulation system can automatically adjust the bucking solution to better describe the combinatorial complexity of the timber trade.

The performance of sustainable wood procurement from local forests to consumers of wood products is not well known. In order to determine e.g. energy efficiency of the cost-efficient log cutting, the supply chain should be considered comprehensively to end-use of biofuels. Actually, the monetary value of the timber trade could be increased, since this might increase annual wood-procurement volumes by providing a successful bio-economic policy to the national governments to advance proposed $100 \%$ carbon-neutral energy base. Based on these facts, as well as on the research-built solid platform, new studies may address a range of emerging issues, and especially fuel efficiency and resource efficiency in general, product quality of different uses, value retention, nutrient removal effects and remediation.

Therefore, the forest engineering community should be focused in the near future on problem-solving issues. Research on problem-solving yielded that major scientific advancements mostly followed a change of how problems were represented. As Ivar Samset, one of the fathers of forest operations mentioned, scientific advancements are mainly happening at so-called "discontinuities", which creates the overall picture of a staircase-type pattern of development. Fully mechanised systems, such as the "harvester-forwarder" system are the results of such a step in the 1960s and 1970s. Canadian and Swedish researchers started to look at the problem from a systems perspective, investigating processing and transportation functions and their interactions instead of looking at tools and machines. Systems engineering and analysis evolved into an own field of science that is nowadays the backbone of the design of complicated engineered systems. Although the success of those methods is evident, there is still a tendency to step down on the scientific staircase and to look at single machines, thus assuming that interactions between functions and machines may be neglected. There is a trend to integrate harvesting systems into whole logistics systems of systems that show even more interdependencies within and between systems. As a consequence, we will observe phenomena that are typical for complex systems, such as emergence and adaptation. Whereas the behaviour of simple systems can be explained with historical data, emerging and adaptive behaviour is hard to predict. There is an urgent need for the forest operations engineering and management community to rethink the value of systems analysis and engineering, as a key to design and continuously improve the forest operations engineering systems of the future.

We would like to use this opportunity to thanks to all the members of the FORMEC International Network attending the $50^{\text {th }}$ Anniversary of FORMEC in Braşov, Romania, as well as to all those contributing to its development and progress. We are looking forward for an excellent event next year! 